\title{
Epilogue: A Multicultural Future
}

\author{
Michael Clyne and James Jupp
}

Unfriendly critics were arguing by 2005 that 'multiculturalism was dead in Australia'. This was based on the approach of the Howard Coalition government, which had gradually run down multicultural programmes and finally eliminated the term from the once again renamed Department of Immigration and Citizenship (DIAC). Emphasis on 'integration', citizenship and values had become official Commonwealth policy, inspired partly by developments in Britain and the European Union that were responding to increased concern at Islamist militancy and refugee intakes ${ }^{1}$. Elections in Canada and New Zealand brought in governments less sympathetic to multiculturalism than their predecessors. The election of two British National Party candidates to the parliament of the European Union caused the British government and opposition to emphasise the same concerns as their Australian counterparts. Even many supporters of multiculturalism began to feel that the 'strict limits' promised in the Galbally report of 1978 ought to be defined and implemented. In 1978 the problem of Islamic fundamentalism had not been considered, but thirty years later it dominated and distorted public and official discussion.

\section{A premature death}

This obituary was premature and unduly pessimistic. In Australia the Laborcontrolled states and territories continued actively to pursue multicultural policies. While control changed in Western Australia, this still left seven of the eight committed to multiculturalism. Much of the support for 'cultural' activity rests at the state level, with the Commonwealth more concerned with migrant settlement. The constitution does not specifically allocate multicultural functions, as these were unknown in 1901. Constitutional power over aliens (51xix) and immigration (51xxvii) justified Commonwealth domination of multicultural policy and its allocation to the Immigration Department for all but a few years.

The election of a Labor government in 2007 did not immediately change matters. Much remained in place, including tests for citizenship and an extended waiting period. The Rudd government committed itself to developing multicultural policies and began a still unfinished national consultation. The multicultural

1 Vertovec, S and Wessendorf, S (eds) (2010). The Multiculturalism Backlash, Routledge, London. 
reality of Australia does not change simply because governments want it to. Governments may alter the sources of immigration but cannot dictate cultural variety in the sense of using languages, forming associations, creating new media, retaining links with the homeland and with relatives elsewhere, and practising religions. The latter is specifically protected by s.116 of the Commonwealth constitution. Other multicultural manifestations might be better protected by a Bill of Rights, as in most other democracies. However that has yet to be developed and has been strongly opposed by several religious denominations. Lifestyles and beliefs have been criticised but not interfered with by the states. Political common sense suggests that the normal and harmless activities of several million voters are best left alone.

\section{Assimilation and diversity}

The 2006 Census, issued just as these controversies were gaining force, showed clearly that political imperatives would prevent any sudden and drastic return to the assimilationism of the 1950s. The loss of John Howard's own electorate of Bennelong, with its large and varied ethnic minority population, underlined this in $2007^{2}$. The census showed that one quarter of the Australian population was overseas-born, that over 40 per cent had one or both parents born overseas, that one in six normally used a language other than English (LOTE) at home, that (apart from Jews and Catholics) over one million identified with religions from Asia, the Middle East and Africa, and that less than two-thirds claimed to be Christians. This was a very mixed population, but still with a majority core of British or Irish descended Anglophone Christian Australians. No other ethnicity threatens this core, but it no longer has a monopoly. The large-scale additions to the population after 2006 included an exceptionally large proportion of temporary workers and overseas students who may not intend to remain in Australia, although many do.

Not all immigrants favour multiculturalism and not all third-generation Australians oppose it, as Andrew Markus makes plain. Not all immigrants are naturalised citizens and hence voters, but the great majority are, with citizenship levels at 96 per cent for Greek and Macedonian Orthodox and Baha'i, at 77 per cent for Muslims (of whom one third were born in Australia) and 76 per cent for Buddhists. However the figures are presented, the 'multicultural constituency' is too large to ignore, even if it is disunited, ambivalent or not identified consistently with one or other of the major parties. For many years Federal election data showed quite clearly that the electorates in which non-Englishspeaking (NESB/CALD) migrants are concentrated almost invariably return ALP

2 Jupp, J (2009b). 'Immigration and Ethnicity', Australian Cultural History, vol.27, 2: 157-166. 
candidates. In 2007, of thirty electorates with one quarter or more speaking a LOTE at home (20 per cent of the total) all but two (Menzies and Melbourne) were won by the ALP. The state-level political parties seem more sensitive to these realities than the national organisations centred on Canberra.

\section{The inevitability of acculturation}

The current size and complexity of the 'ethnic minority' population is, then, too important to be ignored. A further argument has been that while the minorities created by immigration are undoubtedly there they will fade away over the generations. The evidence for this rests heavily on the Europeans who came under the White Australia policy between 1947 and 1973. Census analysis, referred to in this book, gives some credence to this view ${ }^{3}$. There are marked shifts away from the use of LOTEs over three generations ${ }^{4}$. There are rising numbers of cross-ethnic marriages and hence of children from 'two cultures' who are attracted to the 'third' ('Australian'). Acculturation does happen and is inevitable but is not the same as total assimilation, as officially urged before the 1970s. Essentially acculturation refers to language shift and identification with the country of residence rather than of origin, while assimilation means total elimination of any characteristics which differ from those of the majority. With a continuing immigration programme, acculturation is competing with newly arrived ethnicities.

One of the features of multicultural advocacy among the 'communities' has been to ignore or belittle the natural process of acculturation. Irish Australians were pioneers in this denial, claiming Irish origins long after they had lost the Irish language or forgotten where the migrants of five or six generations ago came from. This is marked in the United States where every president (including Obama) spends time and effort finding an Irish ancestor. On this kind of calculation, 60 per cent of the Irish in the world are Americans. The diaspora has been very important in Irish and American politics and is also significant for several Australian communities such as Tamils, Greeks and Jews.

Yet the argument that assimilation is always inevitable and that multiculturalism is, therefore, a declining phenomenon, needs serious appraisal. Even today organisations and services based on the post-war Displaced Persons generation survive and even thrive, despite their original constituents having an average age of more than seventy and despite the collapse of the Communist system which had severed their links with their homelands for over forty years. Total assimilation can be a very long process even when the original overseas source

3 See Khoo (chapter 6) and Inglis (chapter 9), this volume.

4 See Clyne (chapter 4), this volume. 
has dried up, as it has for most southern and eastern Europeans. Moreover many of the ethnic organisations change their emphasis and services to cater for the elderly, with appropriate funding from state agencies other than the Department of Immigration (DIAC

Languages, organisations, media, loyalties and even religions decline and die in isolation. Yet Australia is no longer isolated as it was a century ago. Australians of all origins are now in direct, sometimes instant, communication with their homelands and their relatives. Flights, the internet, mobile phones, electronic media, the whole apparatus of the global village, have dissolved the tyranny of distance. Most immigrant communities in Australia are part of international diasporas, with which they often maintain regular links. Their homeland governments encourage this, especially since the collapse of restrictive Communism. The Greek government has a ministry for overseas Greeks and some Italian provincial governments have similar arrangements for their compatriots. The Indian government has created a category of overseas Indians with a view to attracting their investment and possible return. Diasporas are often as important as homeland influences, particularly those located in Europe and North America. They help to modify the impact of the receiving majority culture in many countries of immigration.

Thus, while a degree of acculturation of individuals over one or more generations will undoubtedly happen, it will not necessarily invalidate the multicultural arrangements in a diverse society. Religious change is likely to be slow. Religions are more likely to inhibit out-marriage than secular allegiances or even language. Studies, such as that of Siew-Ean Khoo (this volume), show quite different levels of intermarriage between birthplace groups. These are not necessarily related only to length of Australian residence. Recruitment has moved out of Europe and towards Asia and the Middle East and arranged and cross-cousin marriages are likely to reinforce the inheritance of ethnicity through generations. As the Canadian category of 'visible' ethnicity acknowledges, many arrivals since the 1970s will continue to look different in the eyes of the majority. Whether they are treated with suspicion will be a major concern of multicultural policies into the distant future, as will measurable inequalities between those of different ancestries.

\section{'Integration' as an alternative}

The tendency to declare multiculturalism 'dead' or 'past its use by date' revived the term 'integration', which was fashionable in Australia for a brief period between 1966 and 1973. With three governments (Whitlam, Fraser and Hawke) dominating Federal politics for two decades (1972-1992) and committed to 
multiculturalism, this alternative faded away. In fact it represented, and may still represent, just another variant of multiculturalism with a less challenging name. 'Integration' accepts that ethnic allegiances will remain and be organised, but argues that they are not the basic building blocks of nation building. These are: acceptance of a set of universally acceptable values; individual access to social and economic improvement; mastery of the official language as the key to education and employment; acceptance of the local citizenship and its benefits and obligations; rejection of violent and revolutionary strategies; making a 'contribution' to society; mixing freely with other citizens of varied origins; being proud of and well informed about the nation's history and achievements. No emphasis is placed on minority cultural or linguistic maintenance, which are seen as private concerns but not divisive.

In practice the state can no more impose integration than it can multiculturalism. Attempts to do so by the Howard government included: setting tests of local knowledge for intending citizens; evading the UN Convention relating to asylum seekers; resisting rights-based legislation; tightening laws against terror; encouraging 'moderate Muslims' to take the lead in Muslim structures; reassertion of national myths such as Gallipoli, the bush and mateship; upholding the role of the monarchy; strengthening the role of religion in education, charity and welfare; favouring private initiative over state control. Most of these assume integration into existing society, rather than major modification to that society to accommodate diversity.

This is a rather motley collection of policies, reflecting the mixed inheritance of the elements that make up the Liberal-National alliance. It contains some contradictions, for example the expectation that migrants should adhere to Australian values and loyalties even when only present on temporary visas (the number of which has greatly increased). Values are difficult to define, being either 'motherhood statements' on the 'do as you would be done by' principle, or high expectations of integrity and honesty which many in business or politics would find preposterous. Regular references to the Judeo-Christian ethic, while excluding Muslims and other religions, ignore the fact that Muslims at least also subscribe to the 'Judeo' ethics laid down in the Old Testament. In practice Australian laws are no longer specifically based on Christian principles but may unconsciously embody them.

Essentially adherence to the rule of law, peaceful resolution of personal or collective conflicts, choice of government through the ballot box, equality of men and women, payment of taxes and other lawful charges, respect for property, control of private prejudices, acceptance of legal obligations such as school attendance or voting, and similar desirable attributes of a dutiful citizen, are very widely spread through Australian society, regardless of ethnic background. 
They are also acceptable in most established democracies. Once the argument attempts to define specifically 'Australian' values, knowledge and practices it comes up against the reality that Australia is a multicultural society, drawing in people from a variety of backgrounds and circumstances over different periods of time. Recognition of this caused changes in the citizenship test away from the 1950 s suburban dream of the former prime minister.

\section{Concrete and measurable integration}

As the various analyses in this book show, there is a great deal of effective integration taking place in Australian society. Ability to speak English, willingness to become citizens and thus voters, obedience to the law, secondgeneration acculturation, relocation to outer suburbia, rejection of political extremes, active interest in sport, religious adherence, regular employment, second-generation educational success, home ownership and many other attributes have all been measured over the past thirty years and found to support the claim that migrants have settled into Australian society very well.

There have been no recorded instances of successful terrorism in Australia, only trials for advocating or plotting terrorism under new laws. There are pockets of disadvantage and criminality in the major cities, but these are not exclusive to migrants in general or to particular ethnic groups. Small minorities have adopted criminal or extremist behaviour, but their backgrounds are very varied. There is no ethnic group which comes anywhere near the complex of social problems characteristic of Indigenous Australians, nor any one with such a consistent history of discrimination, cultural destruction, alienation or rejection.

The studies here suggest that while adaptation and acculturation are difficult and complex social processes, they have largely been achieved in a multicultural public policy environment and a carefully planned immigration intake. Prejudice and xenophobia remain and occasionally burst forth. Politicians sometimes 'play the race card' especially when asylum seekers appear on the horizon. But the studies here suggest that integration, social cohesion and equity have been the overall consequence of the multicultural policies pursued in the past thirty-five years. These approaches lay the foundation for policies which will need to be pursued into the foreseeable future. 


\section{Problems and the future}

Where multiculturalism has failed is mainly due to political timidity or conservatism. As elsewhere public opinion and political reactions have failed to cope with the alleged threat from the Islamic revival. Media and partisan influences have stressed the extreme aspects of Islam elsewhere, without asking how significant these might be in Australia. Issues like the burqua have been blown out of all proportion. This has provoked a defensive reaction from many who do not adopt this form of dress but believe that their religious sisters have a right to use it if they choose. The actual numbers involved are quite tiny, many of them recent converts. The call to recreate the long dead Caliphate is as powerless as traditional appeals for the socialist revolution. Neither is likely to occur. Above all, the advent of very small numbers of asylum seekers arriving by boat, most of them in recent years from war zones in Afghanistan, Sri Lanka and Iraq, has served the conservatives well, with their 2010 election slogan 'stop the boats'. With characteristic timidity the ALP did nothing to effectively counter the picture created by its political opponents. This was left to organisations and individuals largely outside the centres of power, such as the Greens, welfare and religious groups. Ethnic and multicultural organisations were also reluctant to swim against the stream of an indignant public opinion.

For the future it might be desirable to separate multiculturalism from immigration, as the Hawke/Keating governments did by locating the policy within the Department of Prime Minister and Cabinet or as most state governments did by locating it within the powers of the Premiers. Otherwise multiculturalism remains a limited policy, being largely a form of migrant settlement. It becomes mixed up with issues such as the current hostility to a 'larger Australia', asylum seekers and migrant selection. Yet ethnic and religious institutions and practices continue to exist and even flourish several generations away from the original arrival of their founders. Some organisations of Scottish, Cornish, Welsh, German, Chinese, Greek and Italian orientation have survived for well over a century. Experience here and elsewhere has been that ethnic and religious prejudices and loyalties do not die easily. A truly multicultural society does not disappear with the first generation, but our present arrangements assume that it will. Canada recognises this reality more effectively than Australia.

Basic issues at present include the degree of tolerance appropriate for practices which are either currently illegal or undesirable in a liberal, secular democracy. These include the role of women in certain religions (and not just Islam); the extent to which some races (and especially Aborigines) are disadvantaged over the long term; the persistence of ethnic and religious prejudices and discrimination; the role of the media and the education systems in dealing with multicultural issues and realities; the participation of hitherto excluded minorities from the 


\section{Multiculturalism and Integration}

highest political, bureaucratic and social levels; the redefinition of 'Australian' values, practices and traditions to expand their scope away from British and Irish origins; and the public discussion of population and immigration issues free from their use for political advantage. Multiculturalism is a form of nation building and not just aimed at immigrant settlement or combating prejudice. 